\title{
A new bulk-micromachining using deep RIE and wet etching for an accelerometer
}

\author{
Geunbae Lim (Non-member), Seogsoon Baek (Non-member) \\ Samsung Advanced Institute of Technology \\ San 14, Nongseo-ri, Kihung-up, Yongin city, Kyongkido, 449-712, Korea \\ Masayoshi Esashi (Member) \\ Department of Mechatronice and Precision Engineering, Tohoku University, \\ Aoba, Aza, Aramaki, Aoba-ku, Sendai 980-77, Japan
}

\begin{abstract}
A new bulk silicon micromachining suitable for accelerometer and other micromechanical structures is developed. By combining deep RIE, $\mathrm{P}^{++}$diffusion and anisotropic wet etching, surface thin beam structures can be fabricated. This process is applied for small sized and high performance capacitive accelerometer packaged by anodic bonding.
\end{abstract}

Key words : Deep RIE, Anisotropic wet etching, Accelerometer

\section{INTRODUCTION}

The technology of silicon micromachining for the fabrication of sensors and actuators offers the possibility of creating microsystems by silicon batch process. Because it treats not only electrical signals but also various input/output physical signals, the interests in automotive, medical, and chemical fields are growing rapidly.

The general trend towards minimized and optimized system requires simple and high yield process technologies. There are two major process techniques in the MEMS field: surface micromachining and bulk micromachining. These techniques have inherent advantages, respectively. Surface micromachining is profitable for scaling down, compatibility with conventional IC process, and multi-layer structure. Since the main material is a deposited polysilicon (or other material), it is not easy to control its mechanical properties and to make thick structures. On the other hand, bulk-micromachining using single crystal silicon can solve these problems. Anisotropic etching is popular in the bulk micromachining, however, the shape is restricted and scale down is difficult because of the tapered wall ${ }^{(1-2)}$.

In order to realize the successful commercial development of optimized device structures a new bulk silicon micromachining is developed. By using deep RIE, $\mathrm{p}^{++}$diffusion and anisotropic wet etching, surface thin beam structure with any patterns and thick bulk structures can be fabricated at the same time. We fabricated a small size and highly sensitive capacitive accelerometer with fully symmetrical suspension and confirmed its high performance.

\section{NEW BULK-MICROMACHINING PROCESS}

Figure 1 shows the new bulk-micromaching process.

(a) The $\mathrm{p}^{++}$diffusion layer is formed for thin beams and electrical contacts with the metal on the glass.

(b) Deep RIE of silicon is then carried out ${ }^{(3-7)}$.

(c) The exposed sidewalls are etched anisotropically in EDP (Ethylene Diamine Pyrocatechol) etchant ${ }^{(8,9)}$. The side walls of narrow beams are cut off. However in the side walls of wide part, the etching is stopped because (111) planes appear.

(d) The convex corner under the narrow beams are etched out finally except thin $\mathrm{p}^{++}$beams ${ }^{(10,11)}$.

The main three intrinsic advantages of the process.

1) Structural freedom :

It is difficult to fabricate optimally designed structures using the conventional bulk-micromachining process, especially fabricating thick structures.

Thin $\mathrm{p}^{++}$beams can be fabricated by undercutting the beams with anisotropic wet etching, however, the beam orientation is restricted to 45 degree to $\langle 110\rangle$ axis as shown in Fig.2. Corner compensation pattern is required because of the long etching time which results in undercutting of convex corners ${ }^{(12-14)}$. On the contrary, any beam angle for optimized device can be made by using the new process. 


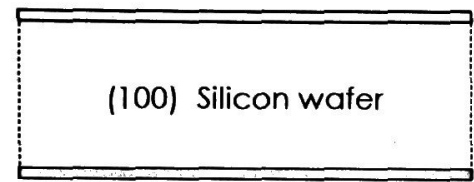

(a) $\mathrm{P}^{+}$diffusion

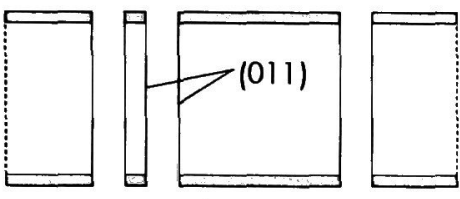

(b) RIE

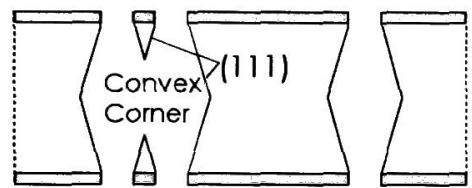

(c) During EPW etching

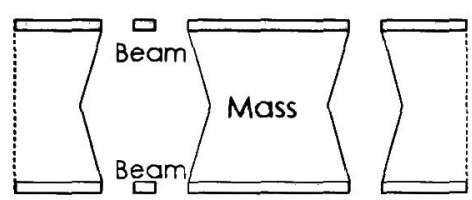

(d) After EPW etching

Fig.1 New bulk-micromaching process

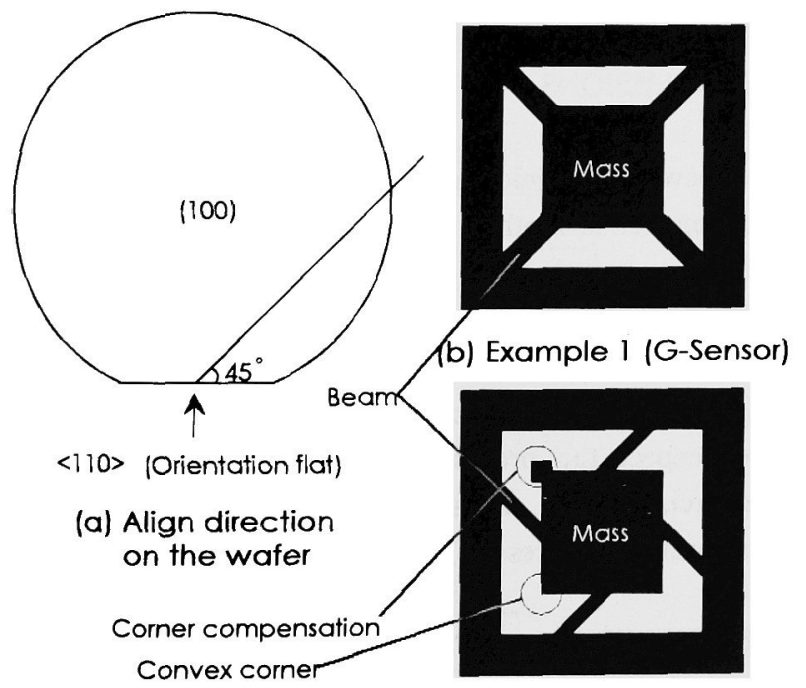

(c) Example 2 (G-Sensor)

Fig.2 Beam angle of the conventional device (G-sensor)
2) Accurate $p^{++}$structure :

Beam width can be controlled accurately in the new process. The $\mathrm{p}^{++}$layer is formed on all the surface and patterned by the following RIE as shown in Fig. 1 (a)(b). On the other hand in conventional process using selective diffusion (Fig. 3) have following problems. During deep diffusion of the $\mathrm{p}^{++}$layer, the side diffusion causes a widening of the $\mathrm{p}^{++}$layer. For example a diffusion of $5 \mu \mathrm{m}$ deep results in $15 \mu \mathrm{m}$ wide structure even if $5 \mu \mathrm{m}$ pattern was used. This problem becomes more recognizable when the process is applied to a scaled down device.

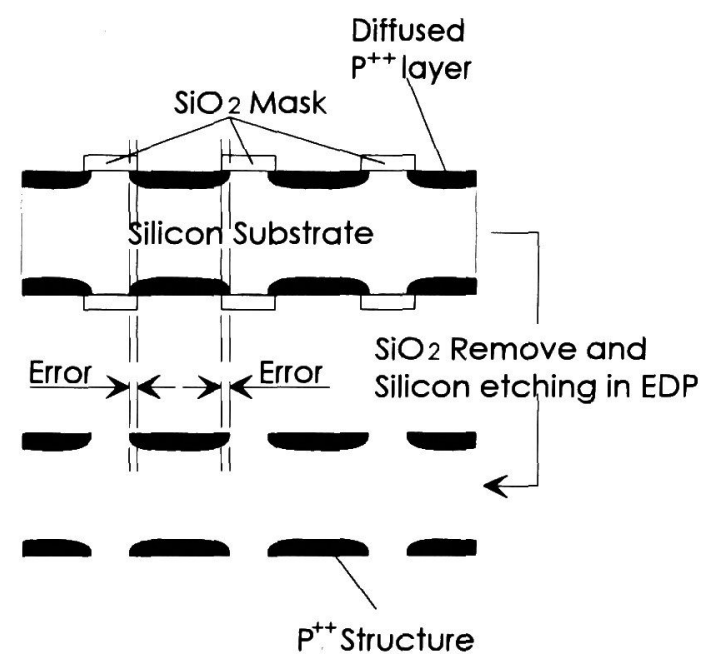

Fig. 3 Beam widening by $\mathrm{p}^{++}$diffusion

3) Simple and high yield process.

Basically, this process can be accomplished using onemask, resulting in alignment-error free. Lithography can be applied on a planer surface and therefore fine pattern can be made.

\section{ACCELEROMETER}

\subsection{Structure}

The structure of the accelerometer made by the new process is shown in Fig. 4. The sensor is composed of a glass-silicon-glass structure. In Fig. 5 the photograph of the accelerometer is shown. $\mathrm{Pt} / \mathrm{Ti}$ electrodes on the glasses are used for capacitive detection, force balancing, electrical contact with post for interconnection and outside electrical pad.

The capacitor gap should be as small as possible not only for high sensitivity but also for wide dynamic range 
due to the generation of a large electrostatic force for force balancing. Narrow gap of $1.5 \mu \mathrm{m}$ is employed by distortionfree anodic bonding using thick $(1 \mathrm{~mm})$ glasses and optimized bonding condition ${ }^{(15-19)}$.

The photograph of the packaged accelerometer is shown in Fig. 6.

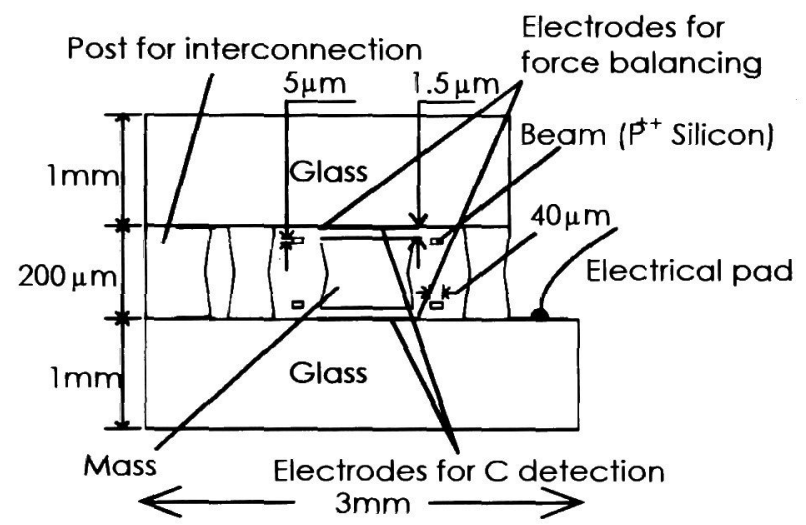

Fig. 4 The structure of an accelerometer

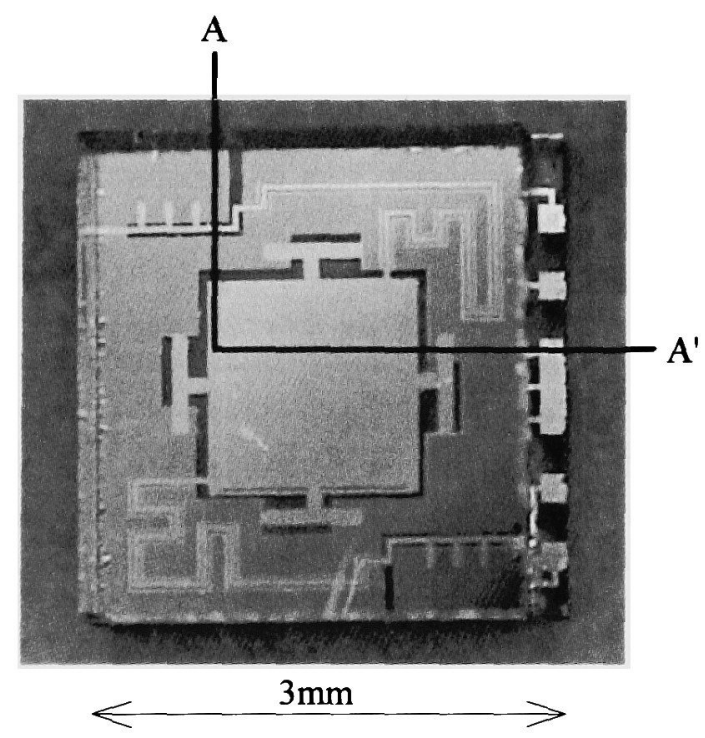

Fig. 5 Photograph of accelerometer

\subsection{Fabrication process of the accelerometer}

The fabrication process is shown in Fig. 7. The device is fabricated on (100)-oriented n-type wafer $(200 \mu \mathrm{m}$ thick).

(a) At first, shallow etched gap in depth of $1.5 \mu \mathrm{m}$ is made for capacitor part, using thermal $\mathrm{SiO}_{2}$ as a mask. Both sides of a wafer is doped with boron to form a $\mathrm{p}^{++}$ layer. The diffusion temperature is $1160^{\circ} \mathrm{C}$ and $\mathrm{p}++$ depth is $5 \mu \mathrm{m}$ with $10^{20} \mathrm{~cm}^{-3}$ boron concentration. (b) The process shown in Fig. 1 is performed as follows.

A resist pattern for RIE mask is formed on the borondoped silicon surface and the deep RIE (STS RIE) is performed through the wafer.

After removing the resist, the substrate is etched in EDP at $115^{\circ} \mathrm{C}$ until convex corner under the $\mathrm{p}^{++}$beam is removed. The beam width is $40 \mu \mathrm{m}$ and the etching time was 18 minutes.

(c) The etched silicon wafer is anodically bonded with glasses from both sides. The temperature and the voltage for the anodic bonding are $320^{\circ} \mathrm{C}$ and 400 volt, respectively.

Finally after dicing, the sensor structure shown in Fig. 7 (e) is obtained.

Figure 8 shows variation of beam structure obtained by this process. Silicon seismic mass is elastically suspended with $5 \mu \mathrm{m}$-thick thin $\mathrm{p}^{++}$silicon beams. This suspension system has fully symmetrical structure for suppressing undesirable off-axis and rotational sensitivities. The RIE process offers optimized beam patterns, because the etching is independent of the crystal orientation whereas the wet etching depends on the crystal orientation.

\subsection{Device performance}

The open loop characteristics of the accelerometer is shown in Fig.9. The base capacitance was $16.5 \mathrm{pF}$ and the sensitivity was $2 \mathrm{pF} / \mathrm{G}$. This shows extremely high sensitivity. Wide dynamic range can be performed by the closed loop operation because of the narrow gap as mentioned above.

\section{CONCLUSIONS}

A new bulk micromachining process suitable for accelerometer and other micromechanical structures have been demonstrated.

The new process using deep RIE and anisotropic wet etching have resulted in accelerometer having good performance and small size.

We expect the process technique will contribute the commercialization of small and high performance micromachine devices

\section{ACKNOWLEDGEMENT}

This work has been done at the Venture Business Laboratory in Tohoku university.

(Manuscript received Jan. 8, 1998, revised March 12, 1998) 


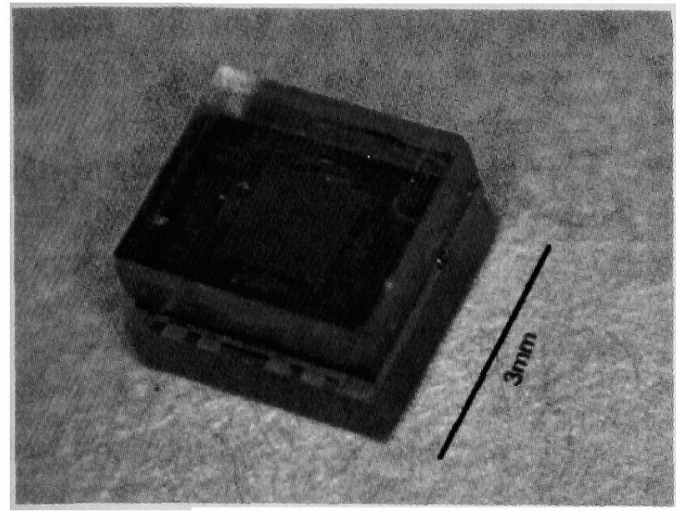

Fig. 6 Packaged accelerometer

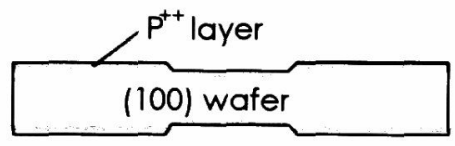

(a)

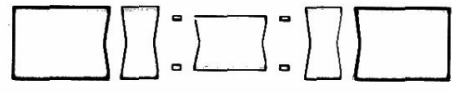

(b)

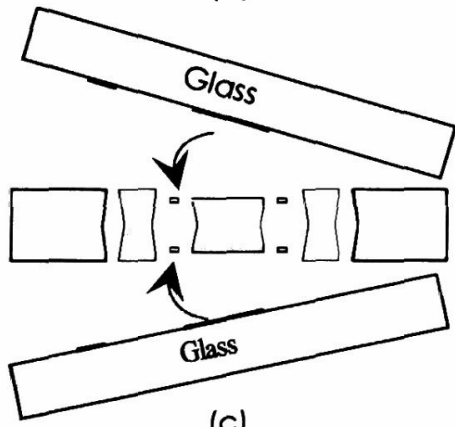

(c)
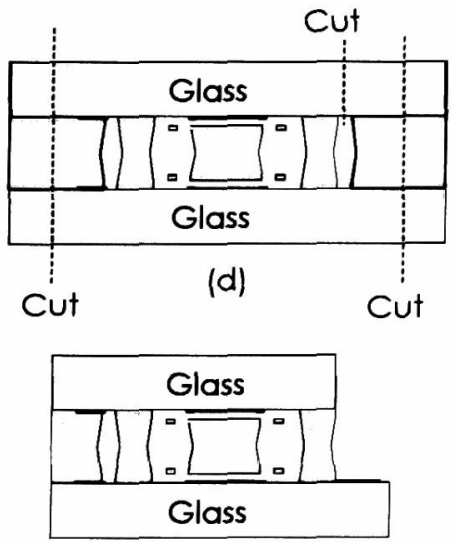

(e)

Fig. 7 The fabrication process of the accelerometer

電学論 $E, 118$ 巻 9 号, 平成 10 年
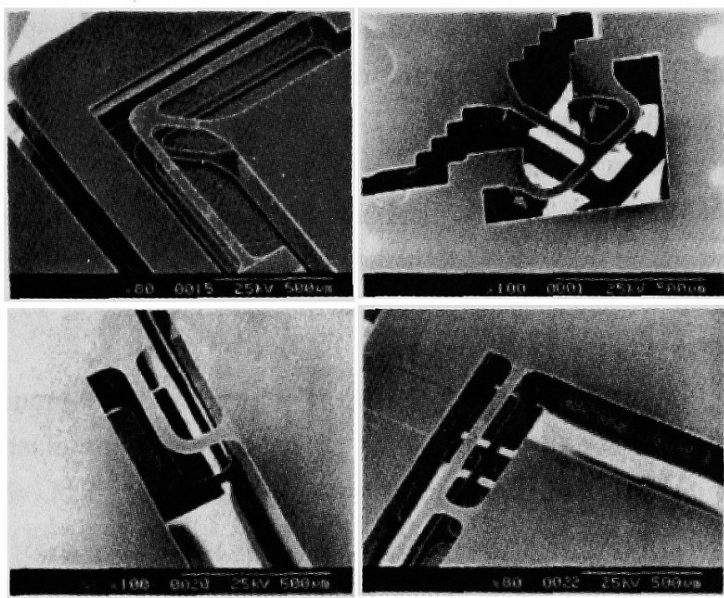

Fig.8 Fabricated beams for accelerometer

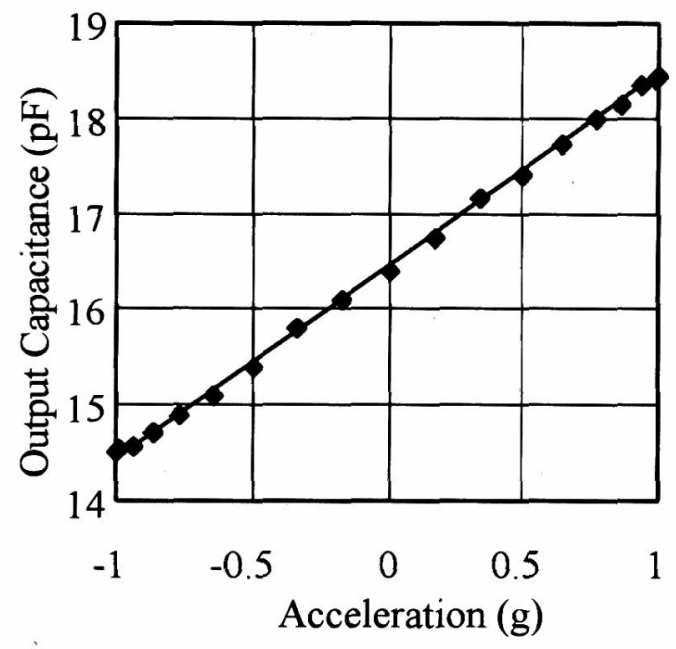

Fig. 9 Characteristic of the accelerometer

\section{REFERENCES}

[1] D. B. Lee; "Anisotropic etching of silicon", J. Appl. Phys., 40, 1969, pp.4569-4574.

[2] K. E. Bean; "Anisotropic etching of silicon", IEEE Trans. Electron Devices, ED-25, 1978, pp.1185-1193.

[3] C. D. Fung and J. R. Linkowski; "Deep Etching of silicon using plasma", Proceedings of the Workshop on Micromachining and Micropackaging of Transducers, Nov. 7-8, 1984, pp.159-164

[4] C. Linder, T. Tschan, N. F. de Rooij; "Deep dry etching techniques as a new IC compatible tool for silicon micromachining", Proceedings, Transducers'91, June 1991, pp.524-527 
[5] M. Takinami, K. Minami, M. Esashi; "High-speed directional low-temperature dry etching for bulk silicon micromachining", Tech. Dig. of the 11th Sensor Symposium, Japan, 1992, pp.15-18

[6]V. A. Yunkin, D. Fischer and E. Voges; "Highly anisotropic selective reactive ion etching of deep trenches in silicon", Microelectronic Engineering, vol.23, 1994, pp.373-376

[7] J. W. Bartha, J. Greschner, M. Puech, and P. Maquin; "Low temperature etching of $\mathrm{Si}$ in high density plasma using SF6/O2", Microelectronics Engineering, vol. 27, 1995, pp.453-456

[8] J. C. Greenwood; "Ethylene diamine pyrocatechol mixture shows preferential etching of p-n junction", J. Electrochem. Soc., 1969, p.116

[9] X. P. Wu, Q. H. Wu, and W. H. Ko; "A study on deep etching of silicon using ethylenediamine-pyrocatecholwater", Sensors and Actuators, 9, 1986, pp.333-343

[10] M. M. Abu-Zeid; "Corner undercutting in anisotropically etched isolation contours", J. Electrochem. Soc., 131, 1984, pp.2138-2142

[11] G. Gerlach; "A novel mask compensation pattern for etched micro-structures with several convex corners" in "Micro System Technologies (ed. H. Reichi)", (SpringerVerlag, Berlin, 1990), pp.545-550

[12] H. Seidel, H. Riedel, R. Kolbeck, G. Muck, W. Kupke and $M$. Koniger; "Capacitive silicon accelerometer with highly symmetrical design" Sensors and Actuators, A21A23, 1990, pp. 312-315

[13] R. Buckhorst, B. J. Hosticka and H. Seidel; "CMOS Readout Electronics for Capacitive Acceleration Sensors", Micro System Technologies 90, Germany, 1990, pp.636641

[14] H. F. Schlaak, F. Arndt, A. Steckenborn, H. J. Gevatter, L. Kiesewetter, H. Grethen; "Micromechanical capacitive acceleration sensor with force compensation", Micro System Technologies'90, Germany, 1990, pp.617-622

[15] D. E. Carlson, K. W. Hang and G. F. Stockdale; "Electrode polarization in alkali-containing glasses", J. Amer. Ceram. Soc.55, 1972, pp.337-342

[16] D. E. Carlson, K. W. Hang and G. F. Stockdale; "Ion Depletion of glass at a blocking anode", J. Amer. Ceram. Soc.57, 1974, pp.295-300

[17] C. D. Fung, P. W. Cheung, W. H. Ko, D.G. Fleming; "Micromachining and Micropackaging of Transducers", Elsevier, 1985, pp.45-61
[18] T. Rogers; "Considerations of anodic bonding for capacitive type silicon/glass sensor fabrication", J. Micromech. Microeng. 2, 1992, pp.164-166

[19] Y. Shoji, M. Yosida, K. Minami and M. Esashi; "Diode Integrated Capacitive Accelerometer with Reduced Structural Distortion", Transducers' 95, Stockholm, Sweden, June 25-29, 1995

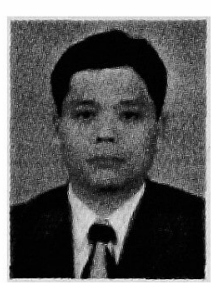

Geunbae Lim (Non-Member) received his B.S and M.S degrees in electronic engineering from Yeungnam University, Korea, in 1990 and 1992, respectively. He received his $\mathrm{Ph} . \mathrm{D}$ degree in precision engineering from Tohoku University Japan, in 1996, and then he joined Microsystems Laboratory, SAIT (Samsung Advanced Institute of Technology), Korea. His research interests are in the areas of silicon sensors, microactuators and nanomachining.

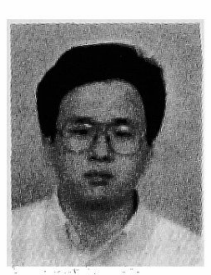

Seoksoon Baek_Non-Member) received the B.S degree from KAIST in 1991. Since 1992, he has been working at SAIT (Samsung Advanced Institute of Technology), in Korea. His current research interests include silicon micro gyroscopes and accelerometer.

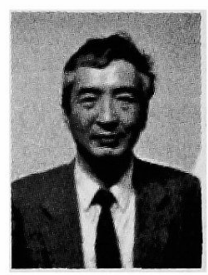

Masayoshi Esashi (Member) received the B.E degree in electronic engineering and the $\mathrm{Ph} . \mathrm{D}$ degree in engineering from Tohoku University, in 1971 and 1976, respectively. From 1976 to 1981 he served as a research associate at the Electronic Engineering Department of Tohoku University. During this period, he worked on biomedical transducers fabricated by micromachining. From 1981 he was an associate professor and since 1990 he has been a professor in the Department of Mechatronics and Precision Engineering of Tohoku University. His current research interest is intelligent sensors and sensor-actuator systems fabricated by micromachining. 